had or were treated for any of 15 predefined comorbidities (categorised into 0, 1, 2, 3 , or $\geq 4$ (Table)). Percentage of number of hours missed due RA (i.e. absenteeism) and presenteeism (10-point Likert scale) were assessed using the Work Productivity and Activity Impairment Questionnaire (WPAI-RA). For the purpose of this study both absenteeism and presenteeism outcomes were dichotomized (no presenteeism/absenteeism versus any) and only patients aged $<65$ yrs were included. Logistic regression analysis were applied to assess the association between number of comorbidities and absenteeism/presenteeism, adjusting for the categorical variables age, gender and education. Chi2-square test was applied to assess frequencies of individual comorbidities between the three employment status groups. Results: 868 participants were included; $91.7 \%$ women with a median symptom duration of 8.3 years [IQR 4.4-13.7]. The average RAID score was 5.2 (SD 2.2). $80.4 \%$ were in paid employment, including those currently on sick leave, $16.9 \%$ stopped early because of their RA and $2.7 \%$ reported stopping early because of other health reasons. In those employed most commonly occurring comorbidities were: back pain $(28.8 \% \%)$, osteoarthritis $(21.5 \%)$, depression $(26.3 \%)$ and anxiety $(22.6 \%)$. Compared to people with RA with no comorbidities, the odds associated with time off work due to RA increased from 1.7 up to 3.4 with increasing number of comorbidities (Table). Although a similar trend was observed for presenteeism, the effect sizes were smaller. Significant differences $(p<0.05)$ in frequencies of the following comorbidities were observed between the three employment status groups (Empl, Stop_RA, Stop_Health, respectively): heart disease $(3.9 \%, 7.9 \%, 20.0 \%)$, blood pressure $(18.0 \%, 29.5 \%, 36.7 \%)$, lung disease $(5.7 \%, 16.3 \%, 26.7 \%)$, diabetes $(4.4 \%, 4.2 \%, 26.7 \%)$, ulcer $(6.1 \%, 11.1 \%$, $13.3 \%)$, cancer $(3.3 \%, 2.6 \%, 13.3 \%)$, depression $(26.3 \%, 33.6 \%, 50.0 \%)$, OA $(21.5 \%, 44.7 \%, 63.33 \%)$, and back pain $(28.8 \%, 48.4 \%, 60.0 \%)$.

\begin{tabular}{|c|c|c|c|c|c|}
\hline \multirow[b]{2}{*}{ Number of comorbidities } & \multirow[b]{2}{*}{$\mathbf{N}$} & \multicolumn{2}{|c|}{ Absenteeism (yes/no) } & \multicolumn{2}{|c|}{ Presenteeism (yes/no) } \\
\hline & & OR & $95 \% \mathrm{Cl}$ & OR & $95 \% \mathrm{Cl}$ \\
\hline 0 & 206 & Ref. & & Ref. & \\
\hline 1 & 174 & 1.70 & $\begin{array}{l}1.06- \\
2.71\end{array}$ & 1.66 & $1.00-2.73$ \\
\hline 2 & 136 & 1.77 & $\begin{array}{l}1.08- \\
2.92\end{array}$ & 1.99 & $1.13-2.86$ \\
\hline 3 & 85 & 1.75 & $\begin{array}{l}1.00- \\
3.08\end{array}$ & 1.53 & $0.82-2.86$ \\
\hline 4-15max & 86 & 3.38 & $\begin{array}{l}1.98- \\
5.78\end{array}$ & 2.64 & $1.28-5.44$ \\
\hline
\end{tabular}

OR=odds ratio; $95 \% \mathrm{Cl}=95 \%$ confidence interval; Comorbidities included: heart disease, blood pressure, lung disease, diabetes, ulcer or stomach disease, kidney disease, liver disease, anaemia or other blood disease, cancer, depression, anxiety, OA, back pain, osteoporosis and Sjögren. Bold figures $P<0.05$

Conclusion: Although the study is cross-sectional and no temporal association can be determined, this study shows that not only personal and work related contextual factors should be considered when preventing worker productivity loss, but also other comorbidities.

Disclosure of Interests: A. Bradshaw: None declared, Ailsa Bosworth Speakers bureau: a number of pharmaceutical companies for reasons of inhouse training, advisory boards etc., K. Walker-Bone: None declared, Laura Lunt: None declared, Suzanne Verstappen Grant/research support from: BMS, Consultant of: Celltrion, Speakers bureau: Pfizer

DOI: 10.1136/annrheumdis-2020-eular.5467

\section{SAT0073 MYOPENIA AGGRAVATES RHEUMATOID ARTHRITIS IN ELDERLY PATIENTS AS A MEDIATOR}

J. D. MA ${ }^{1}$, C. Chen ${ }^{1}$, J. Z. Lin ${ }^{1}$, Q. H. LI ${ }^{1}$, L. F. Chen ${ }^{1}$, Y. H. Xu' ${ }^{1}$, D. H. Zheng ${ }^{1}$, L. Dai ${ }^{1} .{ }^{1}$ Sun Yat-Sen Memorial Hospital, Sun Yat-Sen University, Rheumatology, Guangzhou, China

Background: Ageing affects different systems resulting in a special clinical phenotype of rheumatoid arthritis (RA) in elderly patients who are characterized by higher level of systemic inflammatory and poor function. It also leads to loss of muscle mass causing functional limitation and reduced quality of life. However, little is known about muscle loss in growing elderly RA patients.

Objectives: To explore the characteristics of muscle mass and clinical significance in elderly RA patients.

Methods: Consecutive RA patients were recruited and clinical data including disease activity (DAS28-CRP), function (HAQ-DI) and radiographic indicators (modified Sharp score) were collected. The mass and distribution of muscle were assessed by bioelectric impedance analysis. Myopenia was defined as appendicular skeletal muscle mass index (ASMI) $\leq 7.0 \mathrm{~kg} / \mathrm{m}^{2}$ in men and $\leq 5.7 \mathrm{~kg} / \mathrm{m}^{2}$ in women.
Results: (1) There were 643 RA patients recruited with $82.3 \%$ female, mean age $49.7 \pm 12.9$ years and median disease duration 48 (IQR 21,108) months. There were $414(64.4 \%)$ RA patients with active disease (DAS28-CRP $\geq 3.2$ ) and $229(35.6 \%)$ with remission. (2) There were $165(25.7 \%)$ elderly RA patients (age $\geq 60$ years) with mean age $65.1 \pm 4.5$ years. Compared with young patients (age $<60$ years), elderly RA patients had significantly higher disease activity indicators including PtGA, PrGA, ESR, CRP, DAS28-CRP, DAS28-ESR, SDAI and $C D A I$, higher $H A Q-D I(0.38$ vs. 0.13$)$ and higher modified total Sharp score (mTSS, 16 vs. 9, all $P<0.001)$. There were $288(44.8 \%)$ RA patients with myopenia and elderly RA patients had higher proportion of myopenia than young patients (54.5\% vs. $41.4 \%, P=0.003)$. (3) Among 4 subgroups according to age and ASMI, elderly RA patients with myopenia ( $n=90,14.0 \%)$ had significant higher DAS28-CRP (3.6 vs. 3.0), higher HAQ-DI (0.50 vs. 0.12 ) and higher mTSS ( 21 vs. 7 ) than those in young patients without myopenia ( $n=280$ $43.5 \%$ ), and had higher mTSS (21 vs. 10) than those in elderly patients without myopenia ( $n=75,11.7 \%$, all $P<0.0083)$. (4) Adjusted for confounding factors including gender, disease duration, BMI, smoking habit, RF, ACPA and treatment naïve, multiple linear regression analysis showed that age was positively correlated with DAS28-CRP $(\beta=0.010), \mathrm{HAQ}-\mathrm{DI}(\beta=0.003)$ and $\mathrm{mTSS}(\beta=0.005$, all $P<0.05)$, while ASMI was negatively correlated with DAS28-CRP $(\beta=-0.445)$ HAQ-DI $(\beta=-0.124)$ and mTSS $(\beta=-0.247$, all $P<0.001)$. (5) Mediation analysis showed that old age ( $\geq 60$ years) had total effect on DAS28-CRP $(\beta=0.353)$ HAQ-DI $(\beta=0.132)$ or mTSS $(\beta=7.909$, all $P<0.05)$, but no direct effect on them (all $P>0.05$ ). ASMI fully mediated the associations between old age and DAS28CRP, HAQ-DI or mTSS.

Conclusion: Half of elderly RA patients manifest myopenia which aggravates the whole disease of disease activity, joint function and destruction as a mediator. Myopenia, a neglected comorbidity in elderly RA should be emphasized.

Funding: This work was supported by National Natural Science Foundation of China (81801606 and 81971527,), Natural Science Foundation of Guangdong Province (2018A030313541 and 2019A1515011928), Science and Technology Program of Guangzhou (201904010088).

Disclosure of Interests : None declared

DOI: 10.1136/annrheumdis-2020-eular.1390

\section{SAT0074 RHEUMATOID ARTHRITIS AT TREATMENT WITH BDMARD OR TSDMARD: VACCINATION RATES AND INCIDENCE OF RESPIRATORY INFECTIOUS DISEASES, RESULTS FROM A COHORT}

R. Dos Santos Sobrín ${ }^{1}$, E. Perez-Pampín ${ }^{1}$, N. Pérez Gómez ${ }^{1}$, A. Mera Varela ${ }^{1}$ ${ }^{1}$ Clinical University Hospital in Santiago de Compostela, Rheumatology Department, Santiago de Compostela, Spain

Background: Vaccination regimes have been evaluated for long time in rheumatic diseases, being a strong recommendation to vaccinate against Influenza and Pneumococcus (13 and 23-valent). Rheumatoid arthritis (RA) patients have higher rates of infectious diseases, caused by many reasons, being patient's comorbidities, rheumatic disease and treatments used the most important ${ }^{1-2}$.

Objectives: To analyze the incidence of respiratory infectious diseases in these patients regarding for vaccination status. Also prove the degree of accomplishment of vaccination calendar.

Methods: Patients diagnosed of RA at treatment with bDMARD or tsDMARD, in Rheumatology Department of aforementioned hospital, during Influenza vaccination campaign in 2018 (October 2018 - February 2019) were included. Clinical, demographic and therapeutic data were reviewed. Stata 15.1 was used to perform statistical analysis.

Results: 237 patients finally fulfilled inclusion criteria, excluding deceases or finished treatment (460 patients were diagnosed of RA and 954 patients conform all bDMARD and tsDMARD of Rheumatology Department). Mean age at beginning of vaccination campaign was 61,5 years old (SD 13,6). $79 \%$ were female. Mean time of diagnosis was 15,4 years (SD 9,4). $79,7 \%$ patients receive Influenza vaccine, although higher rates were found in Pneumococcal vaccine (86,9\% 13-valent and 81,8\% 23-valent). Most patients were at treatment with anti-TNF $(57,2 \%$, the most prevalent was etanercept $27,5 \%$ followed by adalimumab $11,0 \%$ and infliximab 10,2\%). csDMARD concomitant was achieved by $67,4 \%$ patients (methotrexate $73 \%$ ) and $61 \%$ receive corticosteroids. Only 3 patients got hospitalized by pneumonia. As opposed, 39 patients suffer from a respiratory infectious disease without hospitalization (mean of 1,33 infections/ patient). After multivariate analysis, only 13-valent Pneumococcal vaccine is related statistically significant with higher rates of respiratory infectious diseases (Chi2=6,25 p=0,012; OR 2,86 Cl95\% 1,22 to 6,68). Other variables analyzed were kind of bDMARD/tsDMARD, Influenza vaccine, 23-valent Pneumococcal vaccine, concomitant csDMARD/corticosteroids, but no relationship was found. Conclusion: Vaccination status is still incomplete in majority of rheumatic patients. Its benefits have been explained in a variety of studies. That is the 
reason why, supporting this study, vaccination status must be checked in the daily practice.

\section{References:}

[1] 2019 update of EULAR recommendations for vaccination in adult patients with autoinmune inflammatory rheumatic diseases. Furer V, et al. Ann Rheum Dis. 2020;79:39-52.

[2] Inmunización y quimioprofilaxis en pacientes con artritis reumatoide. Begazo A. J Sem Reu. 2013;14(2):36-42.

Disclosure of Interests: None declared

DOI: 10.1136/annrheumdis-2020-eular.6019

\section{SAT0075 ABATACEPT IN COMBINATION WITH METOTREXATE IN PATIENTS WITH RHEUMATOID ARTHRITIS ASSOCIATED TO INTERSTITIAL LUNG DISEASE: NATIONAL MULTICENTER STUDY OF 263 PATIENTS}

C. Fernández-Díaz ${ }^{1}$, S. Castañeda ${ }^{2}$, R. Melero ${ }^{2}$, J. Loricera ${ }^{1}$, F. OrtizSanjuán ${ }^{2}$, A. Juan-Mas ${ }^{2}$, C. Carrasco-Cubero ${ }^{2}$, S. Rodriguéz-Muguruza ${ }^{2}$, S. Rodrigez-Garcia ${ }^{2}$, R. Castellanos-Moreira ${ }^{2}$, R. Almodovar ${ }^{2}$, C. Aguilera $\mathrm{Cros}^{2}$, I. Villa-Blanco' ${ }^{2}$, S. Ordoñez ${ }^{2}$, S. Romero-Yuste ${ }^{2}$, C. Ojeda-Garcia ${ }^{2}$, M. Moreno ${ }^{2}$, G. Bonilla' ${ }^{2}$ I. Hernández-Rodriguez ${ }^{2}$, M. Lopez Corbeto ${ }^{2}$, J. L. Andréu Sánchez ${ }^{2}$, T. Pérez Sandoval ${ }^{2}$, A. López Robles ${ }^{2}$, P. Carreira ${ }^{2}$, N. Mena-Vázquez ${ }^{2}$, C. Peralta-Ginés ${ }^{2}$, A. Urruticoechea-Arana ${ }^{2}$, L. M. Arboleya Rodríguez ${ }^{2}$, J. Narváez ${ }^{2}$, D. Palma Sanchez ${ }^{2}$, O. Maiz-Alonso², J. FernándezLeroy $^{2}$, I. Cabezas-Rodriguez ${ }^{2}$, I. Castellví ${ }^{2}$, A. Ruibal-Escribano ${ }^{2}$, J. De DiosJiménez Aberásturi' ${ }^{2}$, P. Vela-Casasempere ${ }^{2}$, C. González-Montagut Gómez ${ }^{2}$, J. M. Blanco ${ }^{2}$, N. Alvarez-Rivas ${ }^{2}$, N. Del-Val ${ }^{2}$, M. Rodíguez-Gómez ${ }^{2}$,E. SalgadoPérez ${ }^{2}$, C. Fernández-López ${ }^{2}$, E. C. Cervantes Pérez ${ }^{2}$, A. Devicente-Delmas ${ }^{2}$, B. Garcia-Magallon ${ }^{2}$, C. Hidalgo ${ }^{2}$, S. Fernández ${ }^{2}$, E. García-Fernández ${ }^{2}$, R. López-Sánchez ${ }^{2}$, S. Castro², P. Morales-Garrido², A. García-Valle ${ }^{2}$, R. Expósito ${ }^{2}$, L. Exposito-Perez ${ }^{2}$, L. Pérez Albaladejo², Á. García-Aparicio², R. Blanco ${ }^{1}$, M. A. González-Gay ${ }^{1} .{ }^{1}$ H.U. Marqués de Valdecilla, Spain; ${ }^{2}$ National Health System, Spain

Background: Interstitial Lung Disease (ILD) is an extra-articular complication of rheumatoid arthritis (RA) that is associated with increased morbidity and mortality. Conventional disease-modifying drugs (DMARDs) such as methotrexate (MTX) have been implicated in the development and exacerbation of a pre-existing ILD.

Objectives: The aim of our study was to check the influence of combined MTX treatment in patients with RA-ILD treated with abatacept (ABA).

Methods: National multicentre retrospective registry of 263 patients with RA-ILD treated with $A B A$. RA was diagnosed according to the ACR classification criteria of 1987 or by the EULAR/ACR criteria of 2010. ILD was diagnosed by high resolution computed tomography (HRCT). In this study we have done a subanalysis of the 46 patients treated with $A B A$ in combination with MTX (ABA+MTX) vs. 217 patients treated with ABA in monotherapy or in combination with other synthetic DMARDs. Efficacy was evaluated according to the following parameters: a) Dyspnoea (MMRC) considering variations $\geq 1 ; b$ ) Lung function test (LFT) considering variations $\geq 10 \%$ in FVC and a variation of DLCO $\geq 10 \%$; c) Imaging test (HRCT) d) DAS28 score e) prednisone dose. Variables were collected at the beginning of the study and at months 3, 6, 12 and then every 12 months until a maximum of 60 months.

Results: 263 patients with ILD associated with RA were included in the study with mean age $64.64 \pm 10$ years. RF or CCPA were positive in $235(89.4 \%)$ and $233(88.6 \%)$ cases, respectively, with a mean follow-up of $22.7 \pm 19.7$ months. Baseline characteristics of both groups are shown in table 1, while data obtained during evolution of this complication are presented in Figure 1.

Conclusion: Despite the baseline differences of both groups, the good evolution in the ABA+MTX subgroup suggests that this therapeutic strategy can be a safe combination for patients with RA-ILD.

\begin{tabular}{lccc}
\hline & $\begin{array}{c}\text { ABA with MTX } \\
(\mathrm{n}=46)\end{array}$ & $\begin{array}{c}\text { ABA w/t MTX } \\
(\mathrm{n}=217)\end{array}$ & $P$ \\
\hline Sex (F/M) & $28 / 18$ & $122 / 95$ & 0.625 \\
Age (years) & $65.11 \pm 10.21$ & $6.2 \pm 9.8$ & 0.202 \\
RF/CCPA + (\%) & $91.3 / 91.3$ & $89.8 / 90.1$ & 0.810 \\
Smoking or past smoking (\%) & 47.8 & 55.1 & 0.417 \\
Follow-up (months) & $22.73 \pm 18.00$ & $22.3 \pm 20.85$ & 0.916 \\
DAS28 at baseline & $4.08 \pm 1.51$ & $4.61 \pm 1.47$ & 0.056 \\
DAS28 at last visit & $3.00 \pm 1.46$ & $3.13 \pm 1.31$ & 0.642 \\
Prednisone at baseline, median (IQR) (mg) & $5(5-7.5)$ & $7.75(5-15)$ & $0.008^{*}$ \\
Prednisone at the end of study, median (IQR) (mg) & $5(1-5)$ & $5(5-7.5)$ & $0.032^{*}$ \\
DLCO at baseline (\%) & $66.85 \pm 19.04$ & $65.43 \pm 18.21$ & 0.823 \\
DLCO at the end of study (\%) & $66.05 \pm 20.95$ & $65.17 \pm 19.72$ & 0.831 \\
FVC at baseline (\%) & $90.06 \pm 17.77$ & $85.40 \pm 21.56$ & 0.164 \\
FVC at the end of study (\%) & $90.58 \pm 15,45$ & $84.21 \pm 21.49$ & $0.038^{*}$ \\
\hline
\end{tabular}

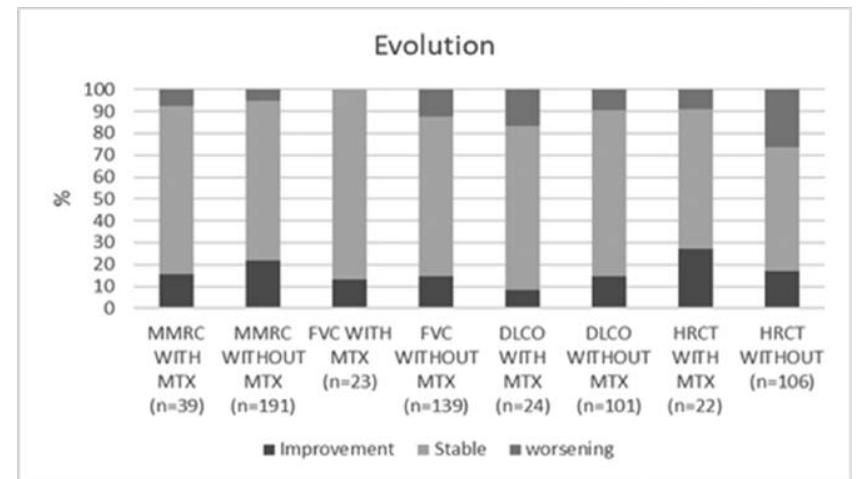

Disclosure of Interests: Carlos Fernández-Díaz Speakers bureau: Brystol Meyers Squibb, Santos Castañeda: None declared, Rafael Melero: None declared, J. Loricera: None declared, Francisco Ortiz-Sanjuán: None declared, A. Juan-Mas: None declared, Carmen Carrasco-Cubero Speakers bureau: Janssen, MSD, AbbVie, Novartis, Bristol Myers Squibb, and Celgene, S, Rodriguéz-Muguruza: None declared, S. Rodrigez -Garcia: None declared, R. Castellanos-Moreira: None declared, RAQUEL ALMODOVAR Speakers bureau: Abbvie, Celgene, Janssen, Lilly, Novartis, Pfizer.

, CLARA AGUILERA CROS: None declared, Ignacio Villa-Blanco Consultant of: UCB, Speakers bureau: Novartis, MSD, Lilly, Sergi Ordoñez: None declared, Susana Romero-Yuste: None declared, C. Ojeda-Garcia: None declared, Manuel Moreno: None declared, Gemma Bonilla: None declared, I. Hernández-Rodriguez: None declared, Mireia Lopez Corbeto: None declared, José Luis Andréu Sánchez: None declared, Trinidad Pérez Sandoval: None declared, Alejandra López Robles: None declared, Patricia Carreira Grant/research support from: Actelion, Roche, MSD, Consultant of: GlaxoSmithKline, VivaCell Biotechnology, Emerald Health Pharmaceuticals, Boehringer Ingelheim, Roche, Speakers bureau: Actelion, GlaxoSmithKline, Roche, Natalia Mena-Vázquez: None declared, C. Peralta-Ginés: None declared, ANA URRUTICOECHEA-ARANA: None declared, Luis Marcelino Arboleya Rodríguez: None declared, J. Narváez: None declared, DESEADA PALMA SANCHEZ: None declared, Olga Maiz-Alonso: None declared, J. Fernández-Leroy: None declared, I. Cabezas-Rodriguez: None declared, Ivan Castellví Consultant of: Boehringer Ingelheim, Actelion, Kern Pharma, Speakers bureau: Boehringer Ingelheim, Actelion, Bristol-Myers Squibb, Roche, A. Ruibal-Escribano: None declared, JR De Dios-Jiménez Aberásturi: None declared, Paloma Vela-Casasempere: None declared, C. González-Montagut Gómez: None declared, J M Blanco: None declared, Noelia Alvarez-Rivas: None declared, N. Del-Val: None declared, M. Rodíguez-Gómez: None declared, Eva Salgado-Pérez: None declared, Carlos Fernández-López: None declared, E.C. Cervantes Pérez: None declared, A. Devicente-DelMas: None declared, Blanca Garcia-Magallon Consultant of: MSD, Speakers bureau: Pfizer, Amgen, Celgene, MSD, Cristina Hidalgo: None declared, Sabela Fernández: None declared, Edilia García-Fernández: None declared, R. López-Sánchez: None declared, S. Castro: None declared, P. Morales-Garrido: None declared, Andrea García-Valle: None declared, Rosa Expósito: None declared, L. Exposito-Perez: None declared, Lorena Pérez Albaladejo: None declared, Ángel García-Aparicio: None declared, Ricardo Blanco Grant/research support from: AbbVie, MSD, and Roche, Speakers bureau: AbbVie, Pfizer, Roche, Bristol-Myers, Janssen, and MSD, Miguel A González-Gay Grant/ research support from: Pfizer, Abbvie, MSD, Speakers bureau: Pfizer, Abbvie, MSD DOI: 10.1136/annrheumdis-2020-eular.1630

\section{SAT0076 \\ VERY ELDERLY ONSET RHEUMATOID ARTHRITIS (VEORA): CLINICAL CHARACTERISTICS AND THERAPEUTIC IMPLICATIONS}

A. García Dorta ${ }^{1}$, C. Almeida ${ }^{2}$, H. D. Marta ${ }^{1}$, L. Cáceres Martín ${ }^{2}$, E. Trujilloº C. Rodríguez-Lozano ${ }^{2}$, I. Ferraz-Amaro ${ }^{1}$, J. C. Quevedo-Abeledo ${ }^{2} .{ }^{1}$ Hospital Universitario de Canarias, La Laguna, Tenerife, Spain; ${ }^{2}$ Hospital Universitario de Gran Canaria Dr Negrin, Las Palmas de GC, Spain

Background: There are differences in the characteristics of patients with Rheumatoid Arthritis (RA) depending on their age at onset with two traditional groups: YORA (young onset RA) and EORA (elderly onset RA). These aspects have not been studied in cases of very late onset ( $\geq 80$ years)

Objectives: To describe the clinical characteristics, treatments and evolution at one year in "very elderly onset RA" (VEORA). Compare these characteristics with YORA (40-50 years) and EORA (60-70 years).

Methods: Retrospective and longitudinal study of RA patients from 2 spanish hospitals. From their databases, VEORA patients were identified and their clinical characteristics were analyzed at onset, treatments at diagnosis and in the first 12 months, as well as DAS28-ESR activity after 1 year. These variables 